\title{
Growth Mechanism of Subcontracting Enterprises Based on Project Knowledge Management
}

\author{
Xiaoping Wang, Nannan Guo and HongYu \\ ${ }^{1}$ Female, Yiwu, ZheJiang, China.researchers in Zheshang research center, Research direction: the \\ enterprise operation and management . \\ ${ }^{2}$ Female, Hebe, Henan, China. Graduate studentln ZheJiang gongshang university. Research \\ direction: PM (project management). \\ ${ }^{3}$ Female, Shaoxing, Zhejiang, China. Dean of school of international education in Zhejinag \\ gongshang university. professor. Research direction: PM (project management). \\ 2391124911@qq.com
}

Keywords: Subcontracting enterprise; Project management; Knowledge management; Project knowledge management; Business growth

\begin{abstract}
The relationships between leading international companies and subcontracting enterprises like that of the relationship between project principal and the party to undertake the project, both in OEM projects. As the core of the cooperation interaction between both of them contains a wealth of knowledge flow. For sub-c enterprises, the international sub-c provides a favorable opportunity to access external new knowledge. Sub-c enterprises should constantly adjust itself to overcome a variety of obstacles that may exist in the project knowledge management process and try to get further knowledge from the OEM project implementation process.
\end{abstract}

\section{Introduction}

Since the reform and opening up of policy, manufacturing in China has entered into the GVC and participated in global manufacturing system successfully with its low-cost advantage. OEM becomes the main business form and the main way that Chinese manufacturing enterprises cooperate with multinational companies in developed countries. At the same time, the OEM is the main method it acquires knowledge and advanced technology from external countries. The second industrialization strategy due to internal and external pressure has forced domestic manufacturing enterprises to gradually realize the importance of the endogenous growth of enterprises based on core competitiveness. Enterprises will be increasingly dependent on knowledge management to gain a competitive advantage which will improve their core competitiveness. Sub-c enterprises, which lack knowledge and technology, not be able to improve their market competitiveness. They should seize every possible opportunity to learn further knowledge from outside. Hobday(1995), found that sub-c is an important mechanism for enterprises in developing countries to obtain foreign advanced technology. 1. The necessity of introducing project knowledge management for subcontracting enterprises.

Features of the Foundry Pattern in the Project Management. Disterer(2012), pointed out that the project can contribute to learning and innovation for an organization. The process of implementation of the project contains a wealth of experience and knowledge. Economic globalization intensifies the competition for limited resources of the world's enterprises. This objectively requires enterprises to improve the efficiency of resource utilization.

China's manufacturing enterprises have inserted into the GVC, with the low cost advantage by "foundry production" way. OEM businesses generally focus on product delivery time, quality and cost of production. Therefore, characteristics of Project Management lurks in the mode of OEM, the study of growth of foundry enterprise can be helped by the MBP Management ideas and methods.

Knowledge Management Should be Consistant Through Out the whole Process of Foundry Enterprise Project Management. With the tendency of globalization competition intensifying, OEM cooperation has become one of international leading companies worldwide. The product line 
in developing countries lacks technical ability and chooses low-end options embedded in OEM by way of leading companies in the developed countries dominate the global value chain. As a result this becomes an important choice to enter the international market and created possible conditions for the foundry enterprises through cooperative learning to get advanced knowledge and technology.

With this project as the core, knowledge transfer and learning motivation exist in the process of OEM cooperation[5]. International leading enterprises want to find the appropriate foundry enterprises and ensure product quality, reduce product cost and shorten delivery time. It will continuously put forward new requirements for the foundry enterprise. While the current enterprise competition has transformed into the competition between international industry chains, the international leading companies have to transfer part of the technology and production technology into foundry enterprises [6]. For foundry enterprises, compared with international advanced enterprise, large gaps exist in production technology, management concepts, management innovation and so on. Foundry enterprises out of envy, will unconsciously pursue the outstanding enterprises and make it as the study object, which spontaneously produces strong learning motivation through imitating high-end climbing the value chain. As a result, foundry enterprises are driving to learn.

Relationship Between Foundry Enterprise Growth and Project Knowledge Management. As the core resources of enterprise survival and development, knowledge becomes more and more important. Therefore, knowledge management has gradually become a key element to acquire competitive advantage. The fundamental purpose of knowledge management is to improve the application value of the knowledge assets thus the value of knowledge can be truly reflected only by specific applications[7]. Foundry enterprise project management can be understood as in accordance with one order for one project. While the project has its own particularity, the project is a temporary activity, which contains knowledge and experience which is likely to be scattered at the end of the project. Therefore, knowledge management and project management should be combined. Project knowledge management mainly includes knowledge identification, acquisition, transmission, sharing, use, innovation and compound effect on project activities through generation and accumulation of knowledge, communication and application management to maximize the value of the project [8]. The technology and knowledge abtained could promote the foundry enterprises to increase the ability of value creation to a certain extent.[9], as shown in Fig. 1.

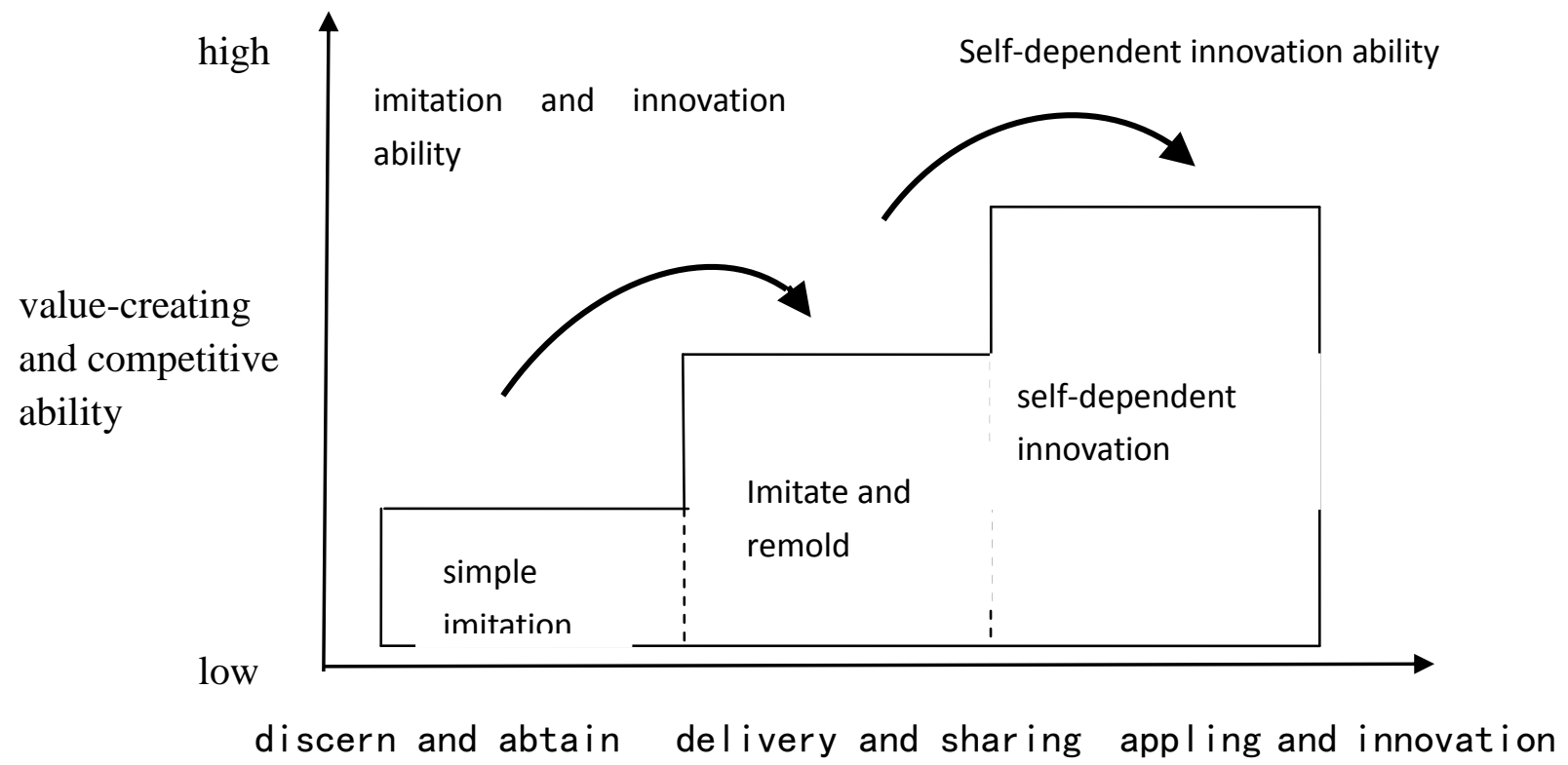

Figure 1. project management 


\section{The Possible Obstacle Factors for Foundry Enterprises to Implement Projects of Knowledge Management}

The key of project knowledge management is how to transform project knowledge into enterprise knowledge effectively through a series of measures. In the process of undertaking international leading enterprises' OEM project, foundry enterprises provide OEM projects with knowledge of production and management, abtain knowledge needed by OEM projects, integrate the original knowledge ,thus creating new knowledge production and management, further sublimate the knowledge to enterprise knowledge and prepare for the next project. The result also enriched the knowledge base of the enterprise, as shown in Fig. 2.

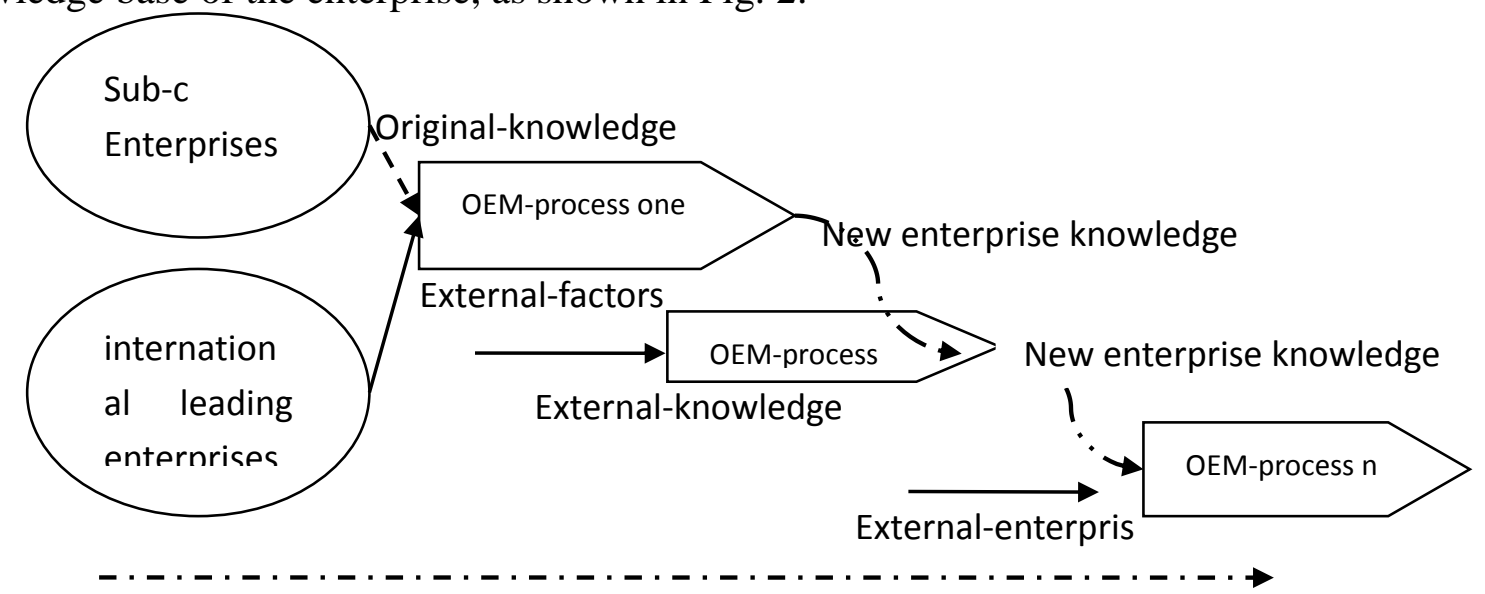

Figure 2. Enterprise

However, the reality shows that foundry enterprise is not ideal in the process of OEM cooperation of project knowledge management. It will be affected by various factors. This article will focus on analyzing the following three possible factors.

The Negligence of Learning Concepts by OEM Enterprise Itself. Learning is the expression of the subjective initiative. It will not happen automatically. It needs the learning motivation of pushing [10]. Cumming' $s$ research pointed out that in the cooperative interaction, if the knowledge receiver lacks willingness to acquire knowledge from each others, knowledge transfer will be very difficult. However, if the receiver has a high degree of willingness to learn, they will have an incentive to formulate related policies based on their own knowledge gaps and take corresponding measures to cooperate knowledge transfer.

Incentive Mechanism and the Knowledge Sharing Atmosphere is Not Strong in OEM Enterprise. Project knowledge sharing is an important part of knowledge management and a process of communication between individual and organizations to realize knowledge transmission and knowledge diffusion among individuals, teams and organizations. Generally, project knowledge sharing consists of internal project knowledge sharing, knowledge sharing between the project and organizational knowledge sharing [11].

Foundry enterprises internal project team is the main interactive body. The team members have access to new knowledge in the process of interaction with the international leading companies. When knowledge can be effectively processed, it can be converted to the competitiveness of the enterprises. However, the reality is that team members often do not actively transfer and share their knowledge for the protection of the intellectual resources itself. From long-term interests, team members will be more concerned about their relationship with the functional managers and ignore the relationship with the project manager which will lead to the result that information is transferred directly to the functional managers.

Guard Against of International Leading Enterprises. From the point of resource based theory, resources which are valuable, scarcity, inimitability and irreplaceable are pivotal for enterprises to acquire sustainable competitive advantage. Foundry enterprises participate in the international contract. Knowledge acquired in the contract project cooperation interaction is unique, and difficult to replicate. However, realizing the effective transfer is key to knowledge and learning through the 
project cooperation is not a simple process. It will be affected by the partners of the relationship, especially that of interest and trust relationship. The willingness of knowledge transfer which international leading enterprises provided for foundry enterprises to a certain extent depends on whether costs consumed on the knowledge transfer can be make up by earnings provided to international leading enterprises and earned by foundry enterprises after learning to improve ability. That is the ratio of cost-benefit.

\section{Countermeasures for Foundry Enterprises to Improve Their Knowledge of Project Management Level.}

Changing Development Ideas and Building Learning Organization. Foundry enterprises should consider the problem of enterprise's sustainable growth for the long run. Value the opportunity that OEM project cooperation interaction with international leading enterprises to learn advanced knowledge from attitude. To build the learning organization in enterprises, integrate learning behavior should be integrated into each stage of enterprise project knowledge management, which will help employees build willingness to learn. Cultivating the consciousness that contemporary workers ready to acquire new knowledge from outside at any time, when in contact with higher management and technical level of international leading companies for foundry enterprises.

Create Project Knowledge Information Management Platform. Since most of the project teams have such characteristics as one-off and temporary. If team knowledge based on project is not effectively managed, it is extremely easy to run off with the end of the project or project members departure. Therefore, specialized knowledge management department should be set up in foundry enterprise and they will responsible for enterprise knowledge management, knowledge building and information environment sharing, cultivating ability of knowledge sharing between team members and promoting project knowledge exchanging and sharing.

Establish Mutual Trust and Beneficial Relations of Cooperation with External Partners. All the cooperation is on the basis of trusts. Inkpen (1998) pointed out that with the trust in relationship growing and mutual understanding deepens, companies will reduce the protection measures of knowledge, thus contributing to knowledge spillover and learning. On the other hand, friction will be produced because of the lack of trust between partners. Therefore, if foundry enterprises want to acquire knowledge from outside, they must establish mutual trust and straight-out cooperation with the outside world (customers, suppliers, etc). Opportunism behaviors which could damage the trust of relationship between parties should be avoided. In order to encourage each other to transfer more knowledge, foundry enterprises should make promises to international leading enterprises or not to market their own brands with customer competition, not to produce the same products for competitors of their customers', thus reducing the international leading enterprises possible risks due to the knowledge transferring or technology sharing and improving trust in them.

\section{Conclusion}

Gaps between foundry enterprises with international leading enterprises in technology, knowledge, resources and management level condemned the absolute dominant position in the international leading enterprises in the industrial chain and foundry enterprises at a disadvantage position. That gap has also made international OEM mode one of the effective ways to obtain advanced knowledge. Sub-c enterprises should constantly adjust themselves to overcome a variety of obstacles that may exist in the project knowledge management process, and try to get more new knowledge from the OEM project implementation process.

\section{Acknowledgements}

This work was supported by ZheJiang Provincial natural science foundation（LY13G020007）.

\section{Literature References}

[1] Hobday M. Innovation in East Asia: the challenge to Japan [M]. Edward Elgar, 1995. 
[2] Chen Guoxu.Foundry enterprise technology learning and technological capability development research [D].Tianjin : Ph.D. Dissertation of tianjin university school of management, 2010.

[3] Qi Anbang.Project Management[M].Tianjin: Nankai University Press, 2003, 12-13.

[4] Disterer G. Management of project knowledge and experiences Journal of Knowledge Management, 2002, 6(5): 512- 521.

[5] Chen Guoxu, He Jinsheng.OEM cooperation learning, knowledge transfer, and technology $[\mathrm{J}]$.zhongnan university of economInternational technology transfer in foundry production, accumulation and industrial upgrading of technology research [J].2012,122-127.

[6] ShangTao, ZhengLianghai.International technology transfer in foundry production, accumulation and industrial upgrading of technology research [J]. Journal of economist, 2013 (7) : 62-68.

[7] Nonaka. A Dynamic Theory of Organizational Knowledge Creation [J].Organization Science, Feb., 1994, 5( 1) : 14- 37.

[8] Hamel, G. Competition for Competence and Inter-partner Learning within International Strategic Alliances [J]. Strategic Management Journal, 1999(12):83-103.

[9] Humphrey, J. and Hubert Schmitz, Developing Country Firms in the World Economy: Governance and Upgrading in Global Value Chains [R]. INEF Report Heft 61, 2002.

[10]Murray P., Myers A. The Facts about Knowledge [Z]. Singapore: C4IT Services of DSTA , 2005.

[11]KongYan.Introduction to the knowledge management in the process of project management [J].GiuShi2012, S2 : 137-138. 